\title{
Functional TRAIL receptors in monocytes and tumor-associated macrophages: A possible targeting pathway in the tumor micro- environment
}

\author{
Manuela Liguori ${ }^{1}$, Chiara Buracchi ${ }^{1}$, Fabio Pasqualini ${ }^{1}$, Francesca Bergomas ${ }^{1}$, \\ Samantha Pesce ${ }^{1}$, Marina Sironi ${ }^{1}$, Fabio Grizzi ${ }^{1}$, Alberto Mantovani ${ }^{1,2}$, Cristina \\ Belgiovine $^{1, *}$, Paola Allavena ${ }^{1,2, *}$ \\ ${ }^{1}$ Department of Immunology and Inflammation, IRCCS-Humanitas Clinical and Research Center, 20089 Rozzano, \\ Milano, Italy \\ ${ }^{2}$ Humanitas University, 20089 Rozzano, Milano, Italy \\ *These authors have contributed equally to this work \\ Correspondence to: Cristina Belgiovine, email: cristina.belgiovine@humanitasresearch.it \\ Paola Allavena, email: paola.allavena@humanitasresearch.it \\ Keywords: TRAIL, TRAIL receptors, apoptosis, tumor-associated macrophages, targeting macrophages \\ Received: February 17, $2016 \quad$ Accepted: April 06, $2016 \quad$ Published: May 13, 2016
}

\section{ABSTRACT}

Despite the accepted dogma that TRAIL kills only tumor cells and spares normal ones, we show in this study that mononuclear phagocytes are susceptible to recombinant TRAIL via caspase-dependent apoptosis. Human resting monocytes and in vitro-differentiated macrophages expressed substantial levels of the functional TRAIL receptors (TRAIL-R1 and TRAIL-R2), while neutrophils and lymphocytes mostly expressed the non-signaling decoy receptor (TRAIL-R3). Accordingly, exclusively monocytes and macrophages activated caspase- 8 and underwent apoptosis upon recombinant TRAIL treatment. TRAIL-Rs were up-regulated by anti-inflammatory agents (IL-10, glucocorticoids) and by natural compounds (Apigenin, Quercetin, Palmitate) and their treatment resulted in increased TRAIL-induced apoptosis. In mice, the only signaling TRAIL-R (DR5) was preferentially expressed by blood monocytes rather than neutrophils or lymphocytes. In both mice and humans, Tumor-Associated Macrophages (TAM) expressed functional TRAIL-R, while resident macrophages in normal tissues did not. As a proof of principle, we treated mice bearing a murine TRAIL-resistant fibrosarcoma with recombinant TRAIL. We observed significant decrease of circulating monocytes and infiltrating TAM, as well as reduced tumor growth and lower metastasis formation. Overall, these findings demonstrate that human and murine monocytes/macrophages are, among leukocytes, uniquely susceptible to TRAIL-mediated killing. This differential susceptibility to TRAIL could be exploited to selectively target macrophages in tumors.

\section{INTRODUCTION}

In the last decade the inflammatory tumor microenviroment has been recognized as a hallmark of cancer and many efforts concentrated in counteracting or limiting this cancer-related inflammation [1-4]. Several studies have now established that local Tumor Associated Macrophages (TAM) fuel the build up of the inflammatory milieu and favour, rather than inhibit, disease progression $[5,6]$. In fact, TAM density in human tumors is usually associated with poor patient prognosis and resistance to therapies [1,
$3,7,8]$. Targeting of TAM for therapeutic purposes has been extensively pursued and is providing positive results in various experimental settings, either as monotherapy or combined with conventional and anti-angiogenic therapies. A number of different approaches has been used to target TAM in tumors: inhibition of their recruitment by using inhibitors of CCL2, alone or in combination therapy $[9,10]$; the use of anti-CSF1R monoclonal antibodies or antagonists to the CSF1R tyrosine kinase [11-13]; as well as strategies aimed to their direct elimination, by inducing apoptosis or inhibition of vital pathways $[14,15]$, including inhibition of 
the mTOR pathway [16-18]. Finally a different approach is the re-programming of their functional phenotype to redirect TAM towards cytotoxic effectors [19, 20]. Our group recently reported that trabectedin, a registered anti-tumor agent of marine origin, has interesting peculiar effects on the tumor micro-environment, in addition to block cell cycles in proliferating tumor cells. In vivo studies in mice and evidence in human patients revealed that at least part of its anti-tumor activity is mediated through the reduction of macrophages in tumors. Mechanistically, trabectedin selectively induced apoptosis in monocytes and macrophages via activation of caspase-8 [14]. Caspase-8 is the prime molecule involved in the extrinsic apoptotic pathway which initiates downstream of death receptors expressed on cell membranes.

Apoptosis activation is a tightly regulated process which involves a number of distinct functional receptors, some non-signaling or decoy receptors, in addition to several adaptor or regulatory proteins. In the case of the extrinsic apoptosis, two major classes of membraneassociated death receptors have been identified: Fas, the receptor for the Fas ligand, and various receptors for the TNF-related apoptosis-inducing ligand (TRAIL). Among the latter, there are two functional receptors, TRAIL R1 (DR4) and TRAIL R2 (DR5) having a death domain in their intracellular portion, and three non-signaling receptors, TRAIL R3 (Dcr1), TRAIL R4 (Dcr2) and osteoprotegerin (OPG), which lack the death domain and are unable to induce apoptosis, but compete with functional receptors for TRAIL binding [21-23]. Binding of TRAIL causes functional receptor oligomerization, with formation of DISC (Death Inducing Signalling Complex) and consequent activation of a caspase cascade that eventually leads to apoptotic cell death [21].

The current dogma is that TRAIL kills tumor cells in vitro and in vivo but spares normal cells that are insensitive to its apoptotic effect [24-28]. Our finding that the compound trabectedin was able to activate caspase- 8 and apoptosis selectively in monocytes, contradicted this dogma and raised the issue of a differential death receptor expression in distinct immune cell subsets. Some recent studies have shown that under conditions of bacterial or viral infections, immune cells become susceptible to TRAIL, as observed with HIV-infected T cells and alveolar macrophages during lung infection with Streptococcus pneumonia [29-31]. However, the vulnerability of primary leukocytes under normal homeostatic conditions is largely understudied. This prompted us to perform an in-depth analysis of death receptor expression and modulation in different leukocyte subsets with a special focus on mononuclear phagocytes in the tumor context.

Here we demonstrate that resting monocytes and macrophages differentially express signalling and decoy TRAIL-Rs and are susceptible to TRAIL-induced apoptosis. As a proof-of-principle, tumor-bearing mice treated with recombinant TRAIL had slowed tumor growth and reduced number of TAM in tumors.

\section{RESULTS}

\section{Characterization of death receptors in human leukocyte subsets}

Our initial observation that monocytes can be targeted by the anti-tumor agent trabectedin through extrinsic apoptosis [14] prompted us to define the expression and modulation of death receptors in human and mouse leucocyte subsets.

Freshly isolated purified human blood leukocytes were tested in flow cytometry; the Fas receptor was expressed at high levels in all leucocyte types (Figure S1A), while the expression of TRAIL-Rs was heterogeneous: the functional TRAIL-Rs (TRAIL-R1 and TRAIL-R2) were mainly expressed on monocytes whereas the decoy receptor (TRAIL-R3) was highly expressed on neutrophils and to a lesser extent on T lymphocytes (Figure 1A-1B); of note, in lymphocytes activated with ionomycin and PMA, TRAIL-R3 was greatly increased (Figure S1B). Despite considerable heterogeneity among the donors, the results clearly indicated that the ratio between functional and decoy receptors, the key point determining TRAIL susceptibility, was in favor of functional TRAIL-Rs for monocytes and of the decoy receptor for neutrophils and lymphocytes. The other non-functional TRAIL-Rs (OPG and TRAIL-R4) were not significantly expressed in resting leukocytes (data not shown).

We next investigated TRAIL-Rs in monocyte subsets on the basis of the expression of CD14, MHC II and the chemokine receptor CX3CR1. TRAIL-R2 was similarly expressed among all monocyte subsets, while TRAIL-R1 was higher in CD14 $4^{\text {bright }}$ monocytes, with the exception of CD14 brigh/MHC II ${ }^{\text {dim }}$ cells. TRAIL-R3, which is usually very low, was higher in $\mathrm{CD} 14^{\text {bright }} / \mathrm{CX} 3 \mathrm{CR} 1^{+}$ cells (Figure S1C).

In monocyte-derived macrophages, expression of all TRAIL-Rs was up-regulated compared to resting monocytes (Figure 1C-1D); of note, M1 and M2 polarized macrophages had similar expression levels, although M2 cells had higher TRAIL-R2 compared to M1 macrophages.

In conclusion, functional TRAIL-Rs are mostly expressed on monocytes and macrophages, while the decoy R3 is preferentially expressed in neutrophils and lymphocytes.

\section{TRAIL receptors in human resident tissue macrophages and tumor-associated macrophages}

We next investigated death receptor expression in a series of normal and tumor tissues, by immunofluorescence. In normal human spleen and lungs, TRAIL-R2 and TRAIL-R3 were barely detectable (Figure 2A-2B). A similar pattern was observed for TRAIL-R1 (not shown). In human tumor tissues, TRAIL-R2 was expressed in the majority of macrophages in hepatic and 
mammary carcinoma samples, and less frequently in colon carcinoma (Figure 2C), but it was not expressed by infiltrating lymphocytes and neutrophils. TRAIL-R3 in tumor tissues was not expressed by any leukocyte type, with the exception of $\mathrm{T}$ lymphocytes in hepatic carcinoma (Figure 2D). Altogether these data show that tissue resident macrophages have no or low expression of functional TRAIL-Rs, while TAM within tumor tissues, but not other leukocytes, do express mainly TRAIL-R2.

TRAIL receptors are modulated by antiinflammatory stimuli in human monocytes/ macrophages

TRAIL receptor modulation was tested upon treatment in vitro of purified monocytes with several cytokines and prototypic stimuli. We observed that LPS, IL-1, TNF $\alpha$, IL-6, as well as IL-4 and TGF $\beta$ did not

modulate TRAIL-R1-2 or the decoy R3, which were actually slightly down-modulated. In contrast, IL-10 and glucocorticoids, strongly up-regulated TRAIL-R1-2 and, to a lesser extent, TRAIL-R3. IFN $\gamma$ had a mild inducing effect on TRAIL-R1 and R3. The results are shown in Figure $3 \mathrm{~A}$ and are expressed as fold increase over untreated cells.

In macrophages differentiated in vitro, IL-10, but not glucocorticoids, induced TRAIL-R up-regulation, while LPS, Pam-Cys and TGF $\beta$ had no effect (Figure 3B). Overall, these data indicate that TRAIL-Rs are positively modulated by anti-inflammatory mediators.

\section{Monocytes and macrophages are susceptible to TRAIL treatment}

The extrinsic apoptotic pathway starts with the activation of caspase- 8 , induced when a death ligand,
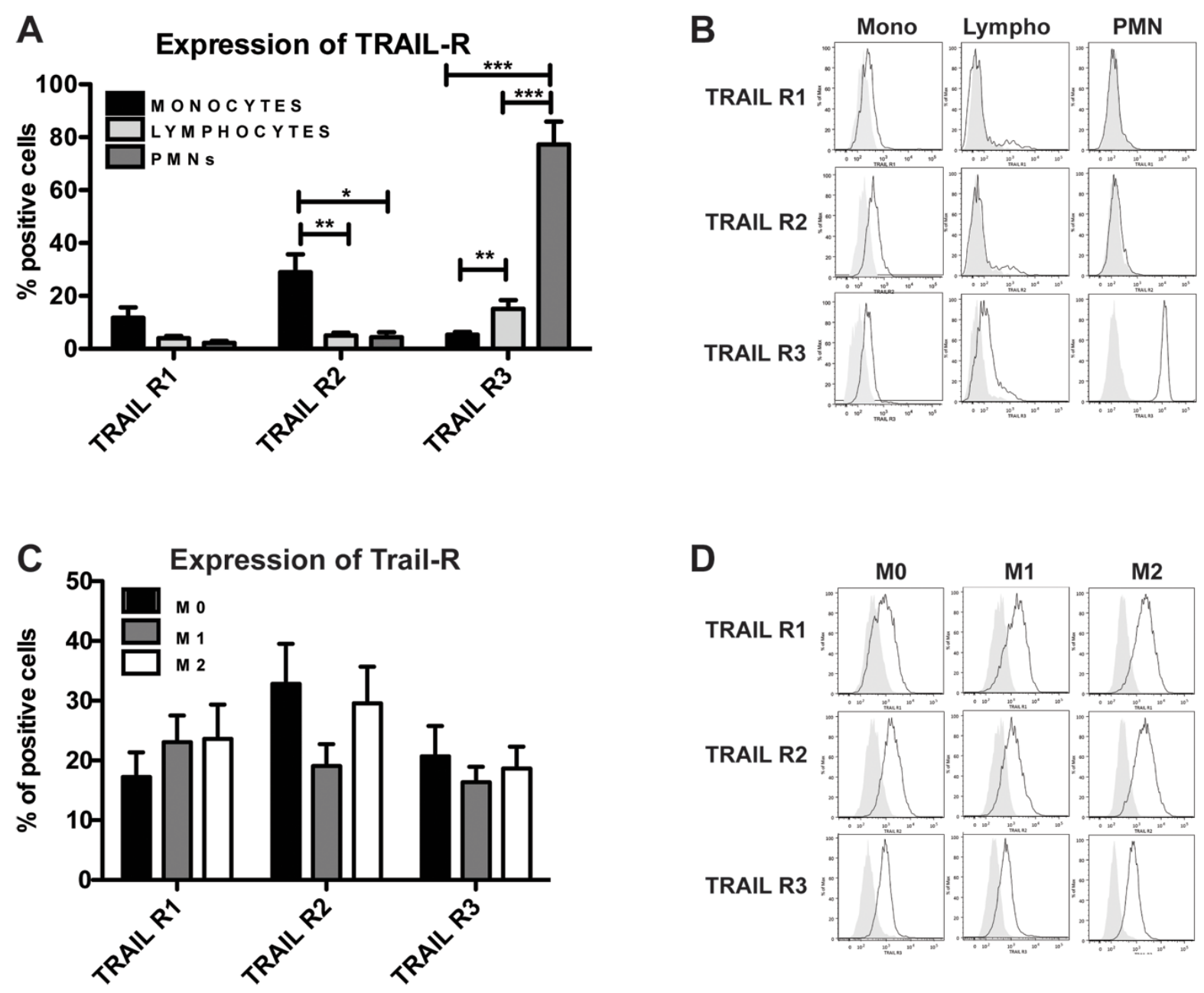

Figure 1: Human monocytes and macrophages express functional TRAIL receptors. Flow cytometry analysis of TRAIL receptor (TRAIL-R) expression. A-B. Freshly isolated purified monocytes, lymphocytes and granulocytes (PMN); C-D. In vitro MCSFdifferentiated macrophages (M0) and polarized M1 (LPS, IFN $\gamma$ ) and M2 (IL-4) macrophages. In A and C, results are shown as \% of positive cells (mean $\pm \mathrm{SE}$ of 10 experiments). In $\mathrm{B}$ and $\mathrm{D}$ Representative plots are shown. Statistical analysis: $* \mathrm{P}<0.05, * * \mathrm{P}<0.01, * * * \mathrm{P}<0.001$ (Student's t test). 
such as FasL, TNF or TRAIL, binds to its receptors. To understand whether the differential expression of TRAIL-Rs in leucocyte subsets corresponds to a different TRAIL susceptibility, we monitored caspase- 8 activation in recombinant TRAIL-treated leukocytes by flow cytometry. We observed that lymphocytes and neutrophils were unable to activate caspase- 8 when treated with TRAIL, while monocytes rapidly activated caspase- 8 in a time dependent manner (Figure 4A). The involvement of functional TRAIL-Rs was confirmed by using antiTRAIL-R1-2 blocking antibodies that inhibited caspase- 8 activation, while anti-TRAIL-R3 or anti-Fas, used as negative controls, had no effect (Figure 4B). Activation of caspase- 8 per se is not sufficient to induce apoptosis; we therefore analyzed the viability of TRAIL-treated monocytes over time. TRAIL induced monocyte apoptotic death in a time dependent manner, reducing their survival by $50 \%$ after $72 \mathrm{~h}$ of treatment (Figure $4 \mathrm{C}$ ). Furthermore,

A

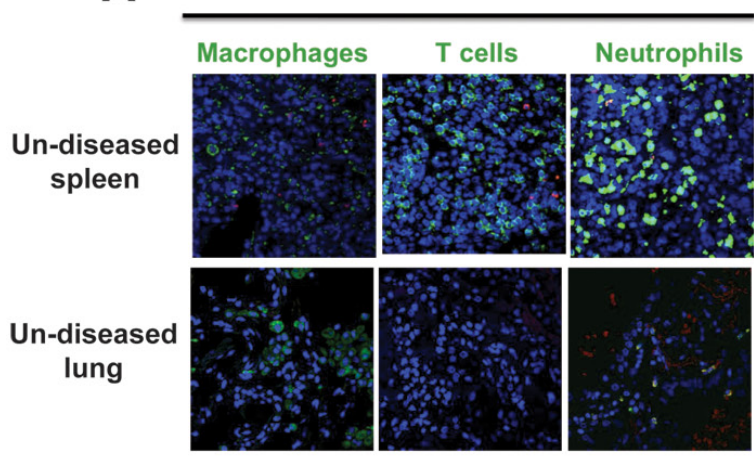

C

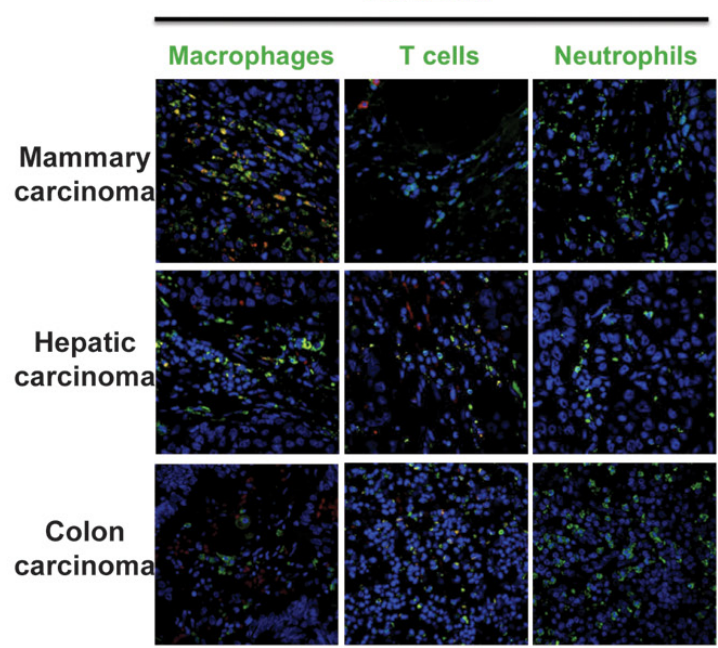

pre-treatment with IL-10 substantially sensitized monocytes to TRAIL-mediated death (Figure 4D).

Caspase- 8 activation and mortality was induced also in cultured macrophages upon TRAIL treatment, as shown by immunofluorescence, but with less efficiency compared to monocytes (Figure 4E); this is probably due to their increased expression of TRAIL-R3 (Figure 1C) and intrinsic resistance to death due to their activated state.

\section{Modulation of TRAIL receptors and apoptosis by natural compounds}

It is known that some natural compounds, such as Palmitate and snail venom, are able to activate caspase- 8 in a TRAIL-independent manner, through upregulation and/or aggregation of death receptors [32, 33]. We investigated the effects of Apigenin, Palmitate, Quercitin, Indole-3-Carbinole (I3C) and the anti-tumor

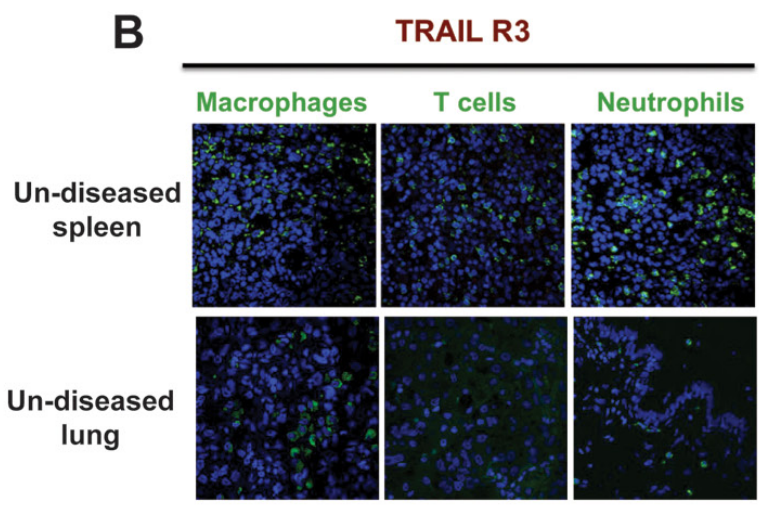

D

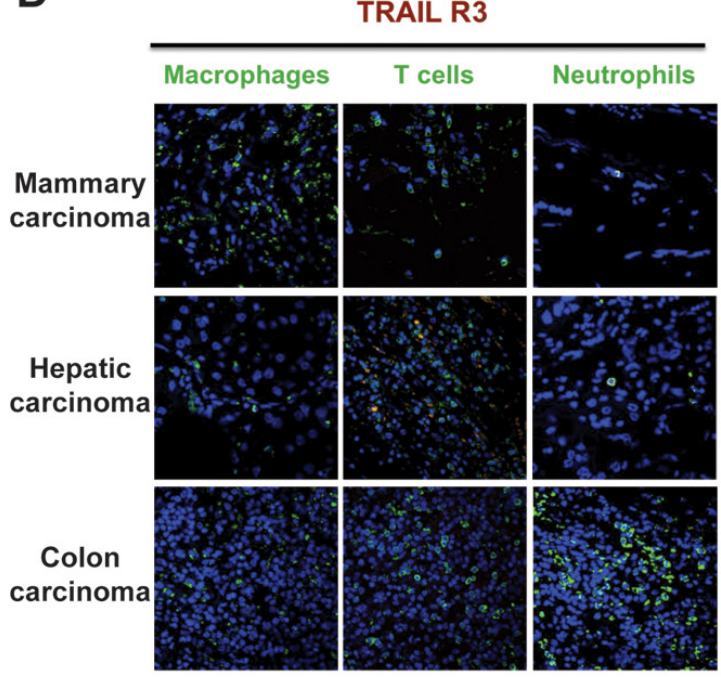

Figure 2: Human tumor-associated macrophages express TRAIL-R2. Immunofluorescence of TRAIL-R2 and TRAIL-R3 and leukocyte markers. A-B. Sections of un-diseased human spleen and lung; C-D. Sections of human mammary, hepatic and colon carcinoma. Macrophages (CD68), T cells (CD3) and granulocytes (myeloperoxidase) are marked in green, TRAIL-R2 and R3 in red and nuclei in blue. Macrophages from tumor tissues, but not from normal tissues, express TRAIL-R2 and do not express TRAIL-R3. 
agent trabectedin on purified human monocytes. These compounds, with the exception of I3C, indeed induced upregulation of TRAIL-Rs, in particular TRAIL-R2 (Figure 5A). Higher expression of TRAIL-Rs was paralleled by increased cell mortality (Figure 5B).

To analyze the mechanism of ligand-independent death, we further investigated by immunofluorescence the expression of TRAIL-R2 and its localization on cell membranes. Upon treatment with Quercitin and trabectedin, the increased expression of TRAIL-R2 correlated with its aggregation into lipid rafts (Figure 5C), in contrast Apigenin and Palmitate were not able to induce this aggregation and the increased death likely occurred via increased expression of receptors.

\section{Characterization of TRAIL receptors in murine leucocyte subsets}

In mice only one functional TRAIL-R is present, DR5 [34]. We first characterized DR5 expression in murine blood leukocyte subsets. As observed in human cells, only murine monocytes expressed appreciable levels of DR5, while the receptor was virtually absent in neutrophils, T and B cells (Figure 6A).
The analysis was performed in two mouse strains (C57BL/6 and DBA2J), with identical results (not shown). Furthermore, in vitro treatment of monocytes isolated from bone marrow with recombinant TRAIL decreased their viability (Figure S2A). The apoptotic effect was modest, compared to human monocytes, but consistently observed.

By immunofluorescence of normal tissues (spleen, skin, liver, lung) we observed that DR5 was not or rarely expressed by leukocytes, with the exception of the spleen, where it was present on $\mathrm{F} 4 / 80^{+}$macrophages as well as by some blood vessels, but not on $\mathrm{Gr}^{+}$myeloid cells (Figure $6 \mathrm{~B})$. This finding was confirmed also on disaggregated splenocytes by flow cytometry (Figure S2B).

We next checked DR5 expression leukocytes infiltrating the transplantable murine fibrosarcoma (MN/ MCA1). TAM expressed substantial levels of DR5, but not other myeloid cells or vessels, as shown in Figure 6C (flow cytometry on disaggregated cells) and in Figure 6D (immunofluorescence on tumor sections). As we observed that not all $\mathrm{F} 4 / 80^{+}$macrophages were $\mathrm{DR} 5^{+}$, we investigated other macrophage markers. In the spleen of tumor-bearing mice (Figure 6E) and in tumor tissues (Figure 6F), DR5 was predominantly expressed by CD206 ${ }^{+}$ and $\mathrm{Tie} 2^{+}$macrophages but not by $\mathrm{F} 4 / 80^{+} \mathrm{MHCII}^{+}$cells.
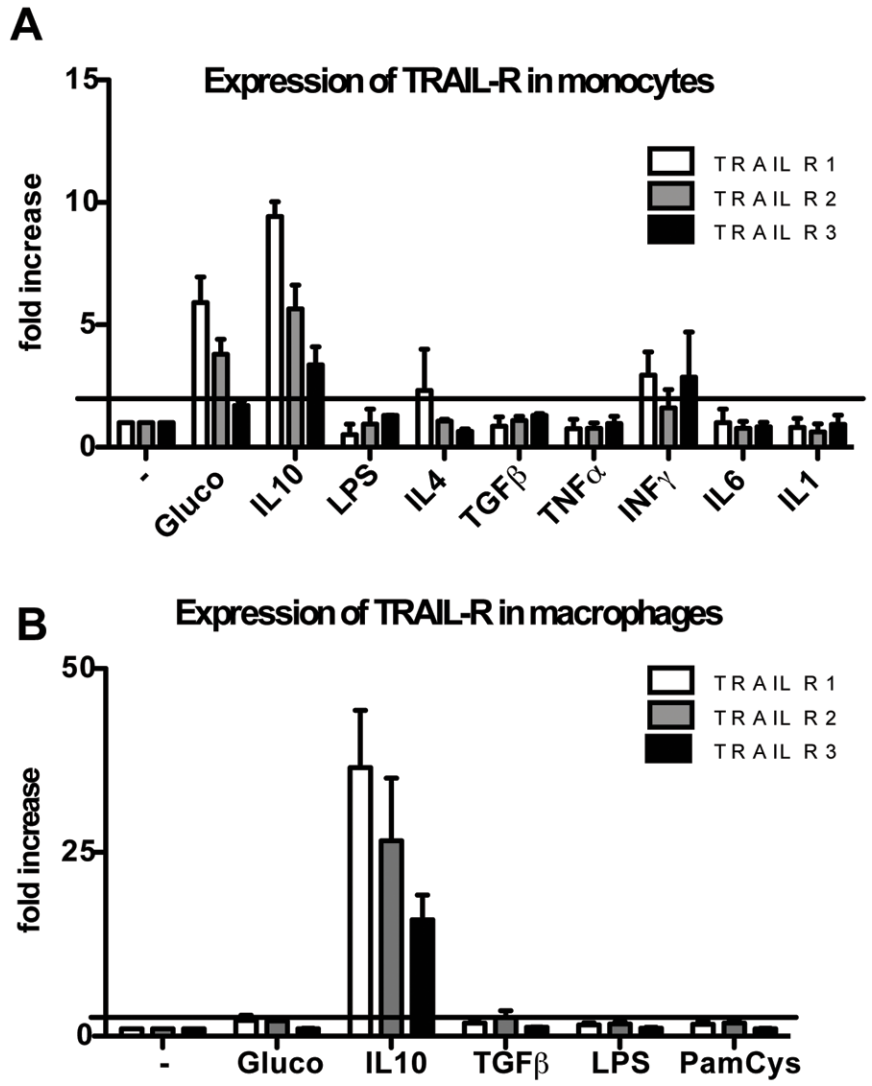

Figure 3: Modulation of TRAIL receptors in human monocytes and macrophages. Glucocorticoids (10 $\left.0^{-7} \mathrm{M}, 24 \mathrm{hrs}\right)$ induce up-regulation of TRAIL-R1-2 in monocytes while IL-10 (25 ng/ml, $24 \mathrm{hrs)} \mathrm{induces} \mathrm{up-regulation} \mathrm{of} \mathrm{TRAIL-R1-2} \mathrm{and} \mathrm{to} \mathrm{a} \mathrm{lesser} \mathrm{extent} \mathrm{of}$ TRAIL-R3 in monocytes (A) and macrophages (B). Results are shown as fold increase relative to untreated cells (mean \pm SE of 3 different experiments). Statistical analysis: $* \mathrm{P}<0.05, * * \mathrm{P}<0.01, * * * \mathrm{P}<0.001$ (Student's t test). 
A

Activated caspase 8

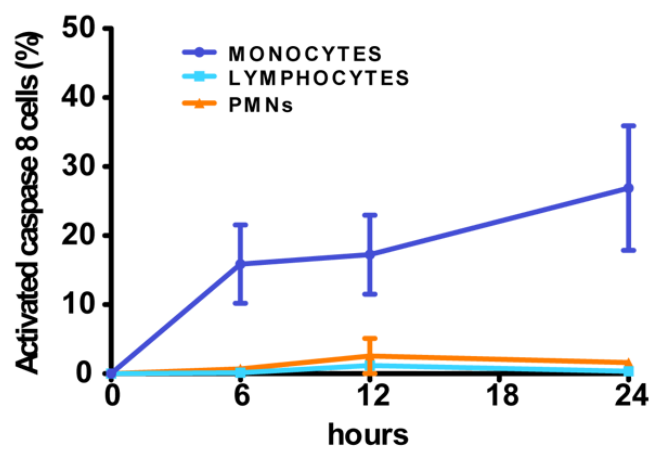

C

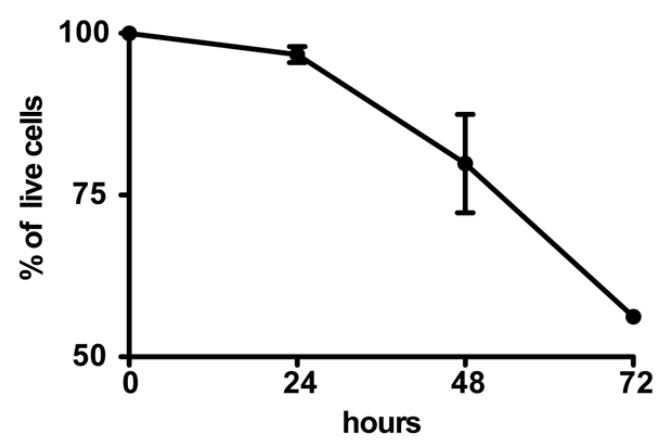

B

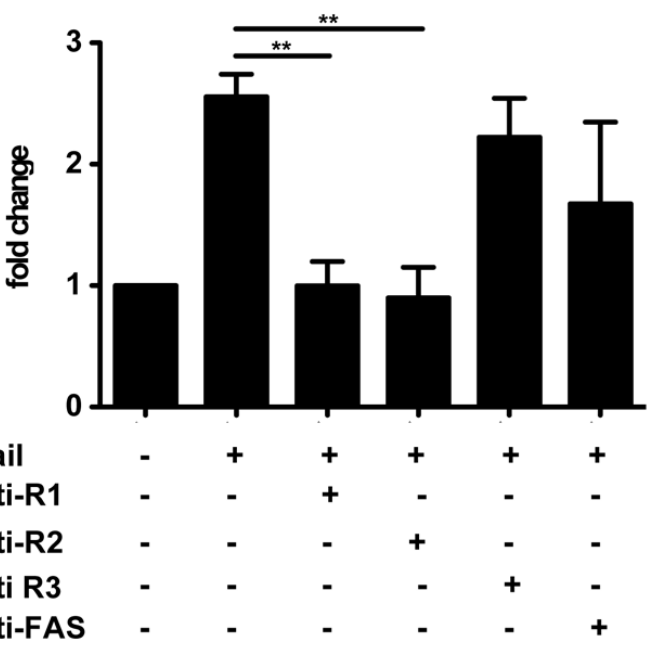

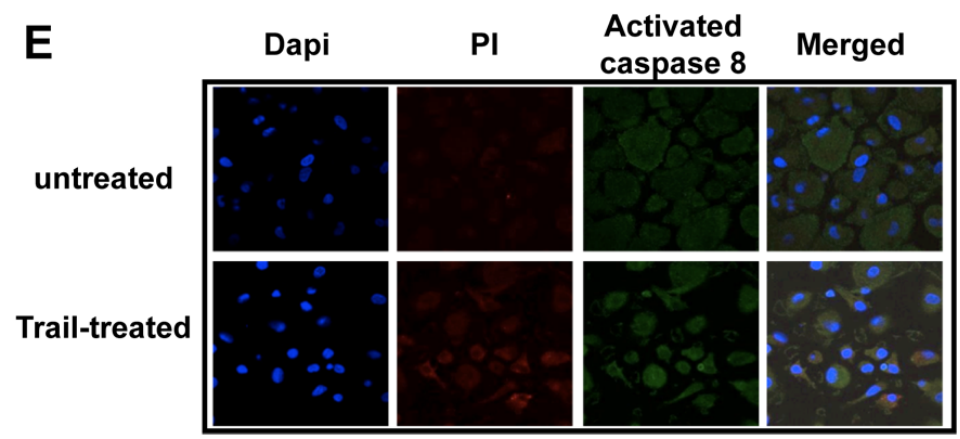

Figure 4: rhTRAIL induces caspase-8 activation and apoptosis selectively in human monocytes and macrophages. A. Activation of caspase- 8 analyzed by flow cytometry after rhTRAIL (SuperKiller) treatment ( $300 \mathrm{ng} / \mathrm{ml}$ ); monocytes but not granulocytes and lymphocytes activate caspase-8. Results are shown as \% of positive cells (mean \pm SE of 5 different donors for monocytes and lymphocytes, 2 for granulocytes). B. Activation of caspase- 8 in monocytes analyzed by flow cytometry; activation is blocked by anti-TRAIL-R1/R2 antibodies. Results are shown as fold change relative to untreated cells. C. Cell viability of monocytes treated with rhTRAIL for up to 72 hrs evaluated with Annexin/PI staining by flow cytometry; results are shown as \% of live cells (Mean \pm SE of 4 experiments). D. Monocyte death upon $24 \mathrm{hrs}$ treatment with rhTRAIL $(300 \mathrm{ng} / \mathrm{ml})$ and IL-10 $(25 \mathrm{ng} / \mathrm{ml})$ alone or in combination; results are shown as \% of dead cells (Mean \pm SE of 3 experiments). Statistical analysis: $* \mathrm{P}<0.05, * * \mathrm{P}<0.01, * * * \mathrm{P}<0.001$ (Student's t test). E. Immunofluorescence analysis of Caspase- 8 activation in in vitro differentiated macrophages after rhTRAIL treatment ( $300 \mathrm{ng} / \mathrm{ml}, 12 \mathrm{hrs})$; Images were taken using confocal microscope: nuclei are shown in blue, PI in red and cleaved-caspase 8 in green. 

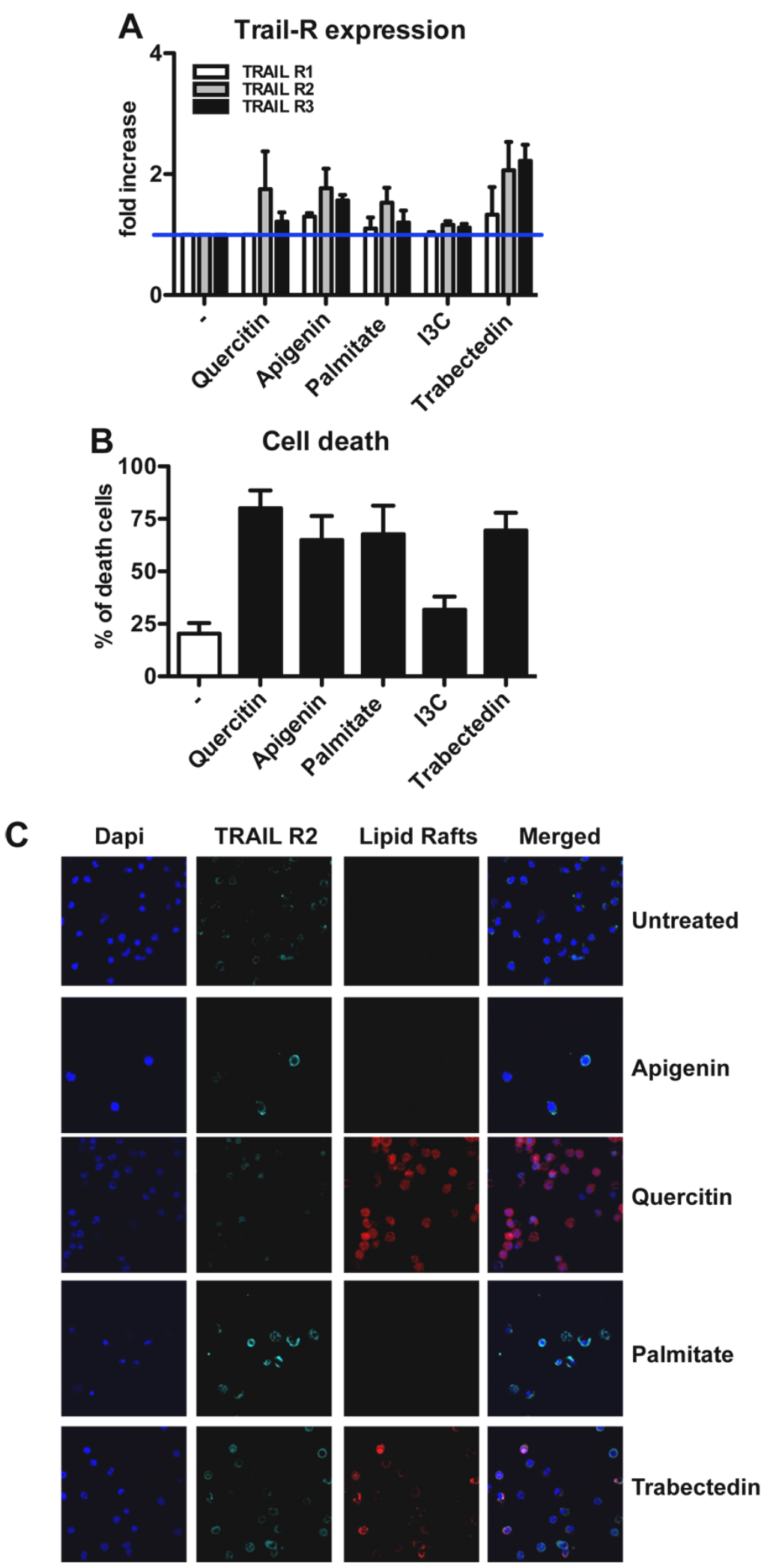

Figure 5: Modulation of TRAIL receptors in human monocytes by natural compounds. A. Up-regulation of TRAIL-R expression upon treatment with Quercitin, Apigenin, Palmitate and Trabectedin for $24 \mathrm{hrs}$; results are shown as fold increase relative to untreated monocytes (mean $\pm \mathrm{SE}$ of 5 experiments). Indole-3-carbinole (I3C) has no effect on TRAIL-R modulation. B. Quercitin, Apigenin, Palmitate and Trabectedin induce cell death after $12 \mathrm{hrs}$ treatment; results are shown as \% of dead cells (mean \pm SE of 5 experiments). C. Immunofluorescence analysis of TRAIL-R2 (light blue) and lipid rafts (red) in treated monocytes. Quercitin and Trabectedin induce TRAIL-R2 co-localization into lipid rafts. Statistical analysis: ${ }^{*} \mathrm{P}<0.05, * * \mathrm{P}<0.01, * * * \mathrm{P}<0.001$ (Student's t test). 


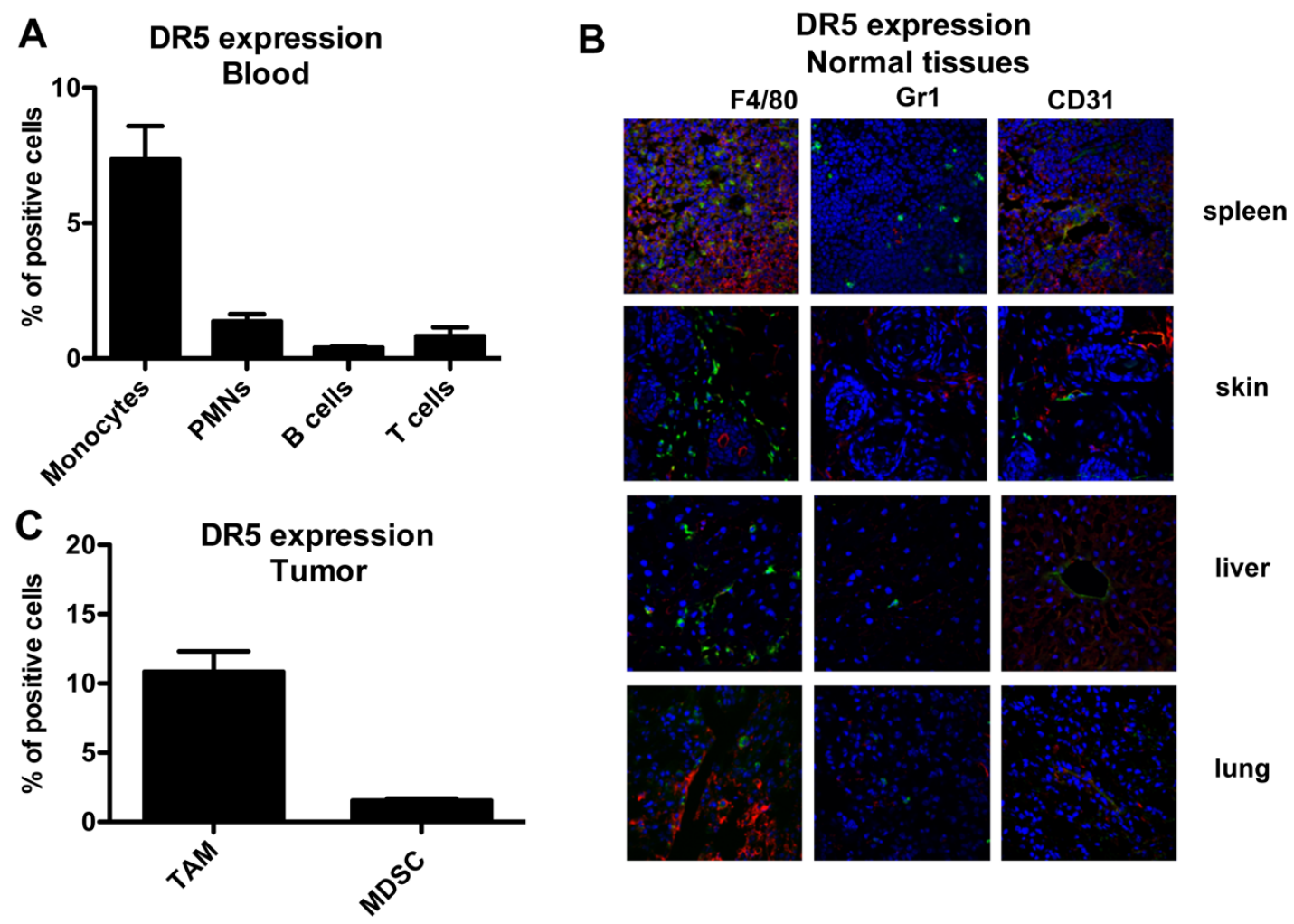

D DR5 expression Tumor Tissue
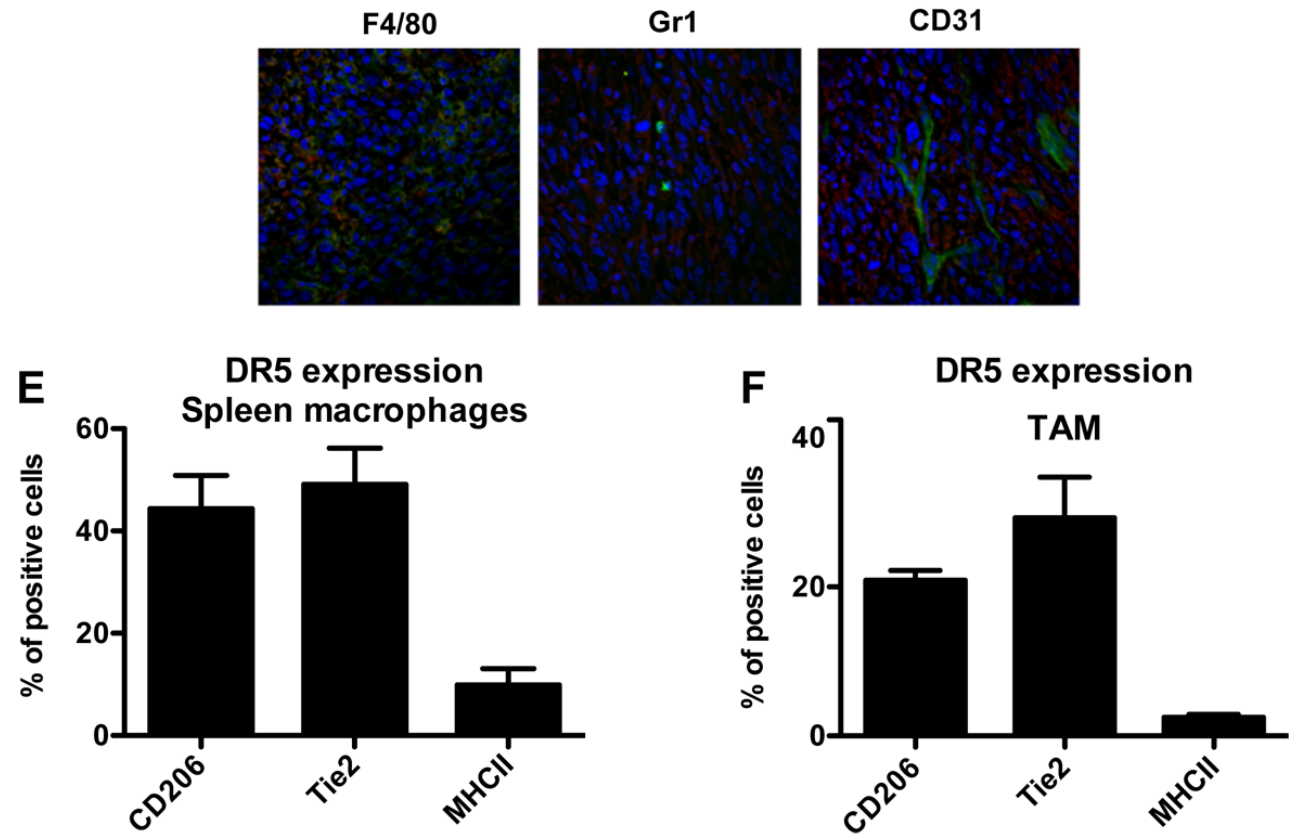

Figure 6: Murine monocytes and macrophages express the functional TRAIL receptor DR5. A. Flow cytometry analysis of murine TRAIL-R (DR5) in blood monocytes, granulocytes, T and B lymphocytes; results are shown as \% of positive cells relative to total $\mathrm{CD} 45^{+}$cells (mean $\pm \mathrm{SE}$ of 29 blood samples). B. Immunofluorescence analysis of DR5, macrophages (F4/80), granulocytes (Ly6G) and endothelial cells (CD31) in normal murine tissues, (DR5 in red, F4-80/Ly6G/CD31 in green and nuclei in blu). C. DR5 expression in TAM and in MDSC from tumor tissues; results are shown as \% of positive cells (Mean \pm SD of 3 experiments); D. immunofluorescence analysis of DR5 in fibrosarcoma tumor tissues (DR5 in red, F4-80/Ly6G/CD31 in green and nuclei in blu). E-F. DR5 expression in CD206+, Tie2 ${ }^{+}$, MHCII+ macrophages from spleen (E) and tumor (F); results are shown as \% of positive cells (Mean \pm SD of 3 experiments). Statistical analysis: $* \mathrm{P}<0.05, * * \mathrm{P}<0.01, * * * \mathrm{P}<0.001$ (Student's t test). 
Overall, these data indicate that, also in mice, the functional TRAIL-R DR5 is mainly expressed by monocytes and macrophages, including TAM.

\section{Targeting of tumor macrophages in vivo by recombinant TRAIL}

In order to understand whether the TRAIL-R pathway could be used to target TAM in the tumor microenvironment, we treated mice transplanted with the MN/ MCA1 fibrosarcoma with recombinant TRAIL. We previously reported that this murine fibrosarcoma is highly infiltrated by macrophages, which have a significant accelerating effect on tumor progression $[14,35]$. We first checked the susceptibility of fibrosarcoma cells to TRAIL treatment in vitro and found that they were intrinsically resistant, while the anti-tumor agent trabectedin, used as positive death inducer, considerably reduced cell viability (Figure S3A). TRAIL treatment of mice significantly impaired tumor growth and spontaneous lung metastasis formation (Figure 7A). Resistance of tumor cells to TRAIL, after in vivo growth and treatment, was confirmed also ex vivo on cultured cells (Figure S3B). In TRAILtreated mice, the number of blood monocytes, in particular the Ly6C ${ }^{\text {high }}$ subset, was significantly decreased 48 hours post-treatment (Figure 7C), as well as the number of TAM in tumors (especially the Ly6C ${ }^{\text {int }}$ subset) as detected by flow cytometry (Figure 7D) and by immunohistochemistry (Figure 7E). Figure 7E also shows the marked reduction of CD206 ${ }^{+}$TAM, the most expressing DR5 subsets; furthermore, the vessel network in treated tumors was appreciably reduced.

Taken together these data demonstrate, in a context where tumor cells are not susceptible, that treatment with TRAIL targets in vivo monocytes/macrophages and significantly reduces tumor progression.

\section{DISCUSSION}

In this study we performed a comprehensive analysis of TRAIL receptor expression and function in blood leukocyte subsets and in tissue resident and tumorassociated macrophages, in mice and humans.

In blood leukocytes, functional TRAIL-Rs (TRAIL-R1-2) are exclusively expressed by monocytes while neutrophils and $\mathrm{T}$ cells have only the decoy receptor TRAIL-R3. The biological significance of this clear-cut segregation is unclear. We can speculate that it is reasonable that monocytes must be kept under strict control, being potentially very reactive cells and with a relatively long life span. Neutrophils, instead, have a life span of few hours in the circulation and the decoy TRAIL-R3 could be helpful to maintain their integrity. Finally, T lymphocytes bear memory for antigens and must be protected from death. Of note, the other death receptor: Fas, is equally expressed and at high levels on all leukocyte subsets. Thus, while functional TRAIL-Rs are present only on monocytes, Fas is present also on neutrophils and $\mathrm{T}$ lymphocytes. The regulation of cell susceptibility to Fas ligand-induced apoptosis could be at the ligand rather than at the receptor level, as it appears to be for TRAIL; in fact FasL is produced and regulated in a strict manner, while TRAIL ligand is usually constitutively expressed by several tissues [24, 25, 27, 28], although it can be induced in immune cells upon stimulation with LPS, IFN $\beta$ or IFN $\gamma$ [36].

Death pathways impact importantly on the immune system development and regulation. TRAIL-deficient mice have been reported to have defects in the thymic negative selection and control of central tolerance, with consequences for the development of autoimmune diseases $[37,38]$ although not confirmed in other studies [39]. Sedger et al. reported that control of aberrant lymphocyte expansion requires both FasL and TRAIL and only the double KO mice show a marked lymphoproliferative disease and severe autoimmunity [40]. Thus TRAIL in tandem with FasL are important to control lymphocyte homeostasis and to limit autoimmunity. As far as innate immunity, and in line with our data on monocytes/ macrophages, TRAIL-R KO mice were reported to have boosted innate immune responses with increased levels of IL-12, IFN- $\alpha$, and IFN- $\gamma$ after pathogen infection [41].

The ligand TRAIL has been reported to mediate also non-apoptotic effects [42]. Besides the activation of death receptors and downstream caspase-dependent apoptosis, TRAIL can activate pro-survival pathways including NF-kB, PI3K, MAPK [43, 44]. Furthermore, TRAILRs have been implicated in liver-associated macrophage inflammation leading to obesity and insulin resistance [45]. On the other hand, other studies suggested that TRAIL can negatively regulate the inflammatory response [46-48]. In this study we investigated whether TRAIL could modify the constitutive or LPS-induced production of several inflammatory mediators (e.g. IL-1 $\beta$, IL-6, CXCL8) in human monocytes, but we did not observe any significant modulation (data not shown).

TRAIL-Rs on leukocytes can be up-regulated under infectious conditions, such as in T cells infected by the HIV virus and alveolar macrophages infected by Streptococcus pneumonia [29, 31]. In our study, the analysis of TRAIL-R modulation on monocytes and macrophages revealed that pro-inflammatory cytokines have no significant role, while cytokines with anti-inflammatory properties such as IL-10 and glucocorticoids strongly up-regulate TRAILRs. A possible scenario could be that at the peak of an acute inflammation, when inflammatory monocytes have concluded their role, endogenous corticoids and IL-10, involved in the resolution phase, increase the number of TRAIL-Rs on monocytes and facilitate their apoptotic death and final disposal. If this is the case, it would be of interest to investigate TRAIL-R expression in monocytes/ 
A

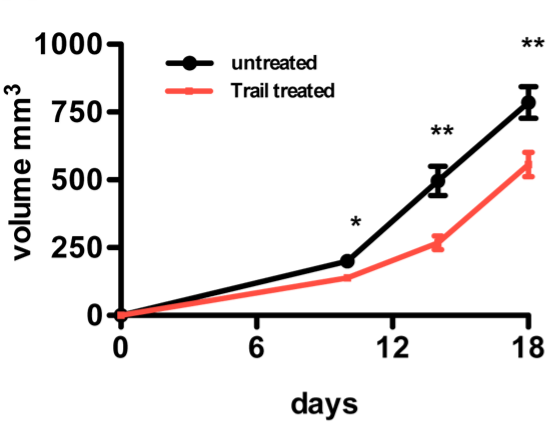

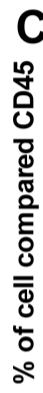

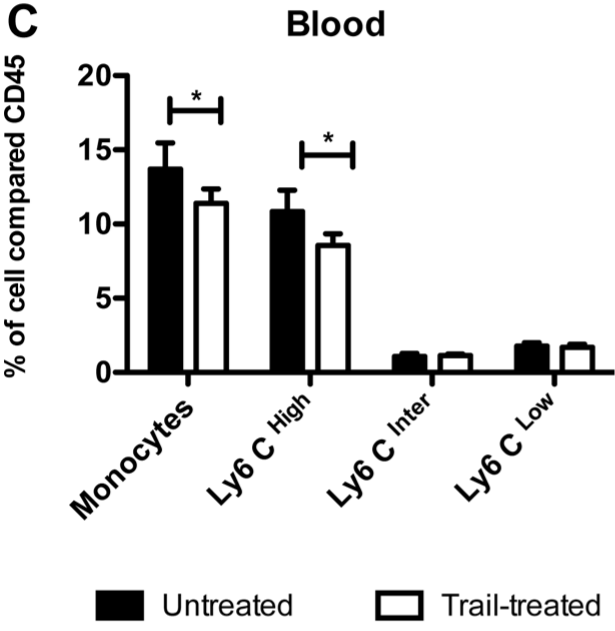

B Metastases

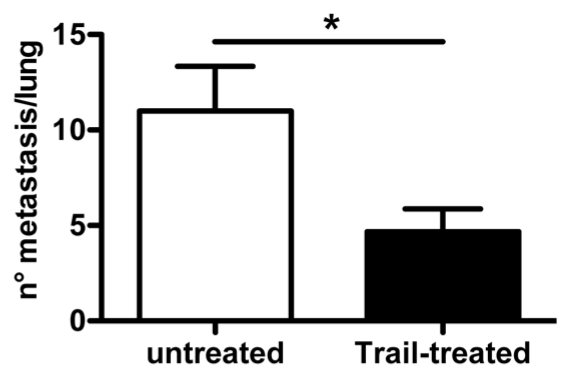

D Tumor

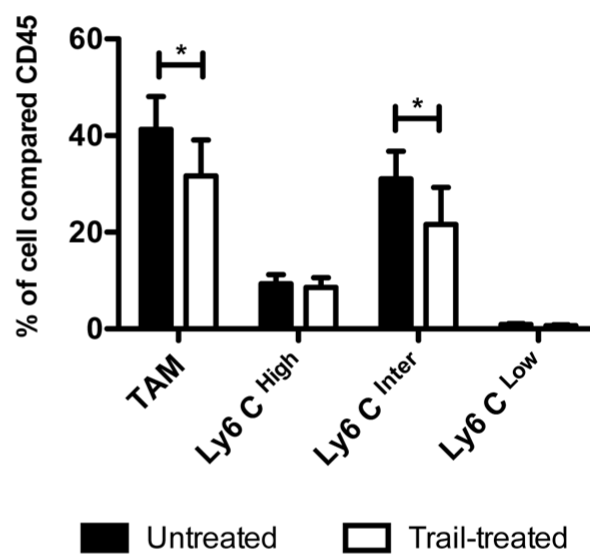

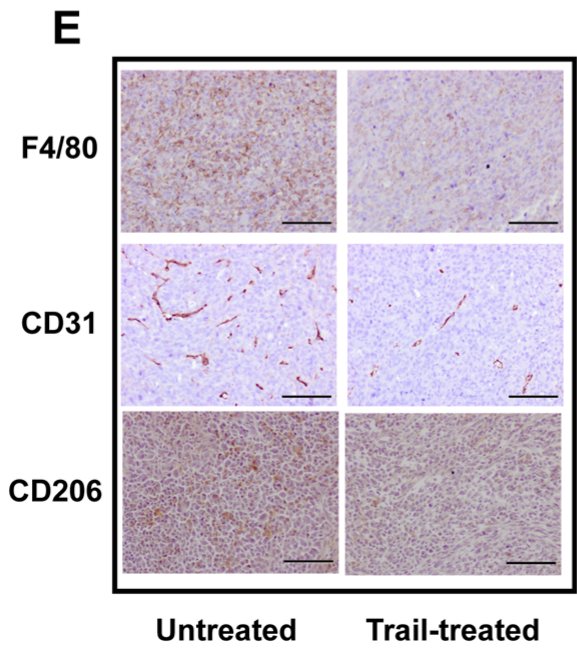

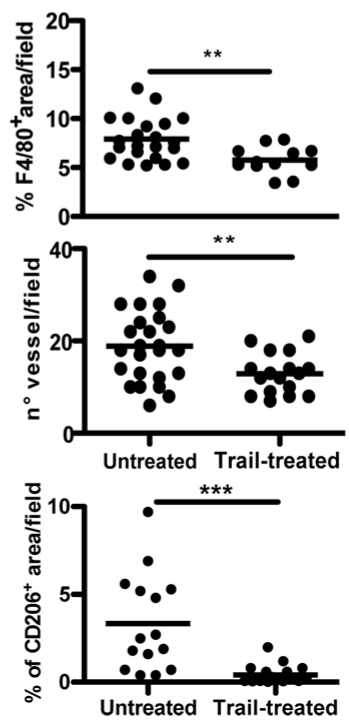

Figure 7: In vivo effects of TRAIL treatment on TAM and tumor growth. A-B. Anti-tumor effect of TRAIL treatment ( $0,01 \mathrm{~g} /$ $\mathrm{kg}$ ) on primary tumor growth and spontaneous lung metastases (mean $\pm \mathrm{SE}, 7$ mice per group; representative experiment of two performed with similar results. C. Flow cytometry analysis of blood monocytes from TRAIL-treated or untreated mice; monocytes and in particular Ly6 $\mathrm{C}^{\text {High }}$ expressing monocytes are significantly reduced after $48 \mathrm{hrs}$ treatment. D. Flow cytometry analysis of TAM from TRAIL-treated or untreated mice; TAM and in particular the Ly6 $\mathrm{C}^{\text {Inter }}$ subset are significantly reduced after treatment; in both $\mathrm{C}$ and $\mathrm{D}$ results are shown as $\%$ of positive cells relative to total $\mathrm{CD} 45^{+}$cells (mean $\pm \mathrm{SE}, 7$ mice per group) E. Immunohistochemistry of tumor sections from TRAILtreated and untreated mice stained for F4/80, CD31 and CD206. The immunoreactive area for macrophages (F4/80, CD206) and number of vessels (CD31) are shown on the right panels. Results are calculated as mean from five microscope fields for each sample, 7 mice per group. Images were analyzed using Image-Pro Analyzer software. Original magnification $20 \mathrm{X}$. Statistical analysis: $* \mathrm{P}<0.05$, $* * \mathrm{P}<0.01$, $* * * \mathrm{P}<0.001$ (Student's t test). 
macrophages under conditions of chronic non-resolving inflammation.

The other interesting result of this study was the finding that, in both mice and humans, tissue resident macrophages do not usually express TRAIL-Rs (with the exception of murine splenocytes), while macrophages infiltrating the tumor micro-environment are clearly TRAIL-R positive. This divergent expression could be explained with the different origin of resident peripheral macrophages (mainly embryonic precursors derived from the yolk sac) and of TAM (circulating monocytes, which express TRAIL-R1-2) [49]. Furthermore, the tumor microenvironment is usually rich in IL-10, which is the major regulator of TRAIL-Rs among the factors tested in this study.

Another myeloid cell type associated to cancer is the heterogeneous population of MDSC. Condamine et al reported that MDSC cells from tumor-bearing mice are susceptible to TRAIL-induced apoptosis and that under conditions of endoplasmic reticulum (ER) stress the DR5 receptor is up-regulated [50]. In our study, MDSC from spleens of tumor-bearing mice expressed low levels of DR5 and to a much lower extent compared to macrophages. It may possible that different isolating techniques and distinct anti-DR5 antibodies may account for this discrepancy. In the tumor micro-environment, Wilson et al. reported that endothelial cells in cancerassociated vessels express DR5 and that TRAIL may function as a tumor vascular disruption agent [51]. In our fibrosarcoma model, we only sporadically observed receptor positivity co-localized with CD31 staining; however, a marked effect was found on the vessel network after in vivo TRAIL treatment, although it cannot be excluded that this is an indirect effect caused by the reduced macrophages.

The finding that TAM have functional TRAILRs bears interest for therapeutic implications. In the last few years it has become increasingly clear that targeting of tumor macrophages is a promising approach to limit tumor progression. The most studied strategies have used inhibitors to the receptor kinase specific for mononuclear phagocytes (M-CSF-R). Several different inhibitors are now available; including monoclonal antibodies and small compounds, and their effects in experimental mouse tumor models is highly promising. Another approach is to limit the recruitment of circulating monocytes at tumor sites by interfering with their response to chemoattractants [13, 52], or to re-activate macrophage cytotoxic potential with agonist anti-CD40 antibodies, TLR agonists or low dose irradiation $[53,54]$.

As a proof of principle that TRAIL-Rs on TAM constitute an interesting molecular target to induce their apoptosis, we treated tumor-bearing mice with recombinant TRAIL and observed a significant decrease of TAM and of circulating monocytes; even if tumor cells were completely resistant to TRAIL-induced apoptosis, a significant slow down of primary tumor growth was noted, as well as a reduction in the number of spontaneous lung metastasis. These results, therefore, constitute the rationale to consider TRAIL therapy as an approach to target TAM, even in contexts where tumor cells have acquired resistance to TRAIL although this remains to be demonstrated in more relevant clinical settings.

In general, TAM have a M2-like phenotype but their heterogeneity is emerging in the last years and different patterns can be found in different tumor types as well as along tumor progression $[4,55]$. In our fibrosarcoma model, the receptor DR5 was predominantly expressed by $\mathrm{CD}^{206^{+}} \mathrm{Tie}^{+}$TAM rather than by the fewer MHC II ${ }^{\text {high }}$ TAM; thus DR5+ TAM displayed a typical phenotype of M2-polarized macrophages [7, 56]. This was in part consistent with the results of in vitro differentiated human macrophages where TRAIL-R2 was indeed higher in M2 than in M1 macrophages.

There is considerable interest in the potential role of TRAIL in cancer therapy [24, 26, 27, 57-59]. Although in the past 15 years the clinical results have been quite disappointing, as many tumors showed intrinsic or acquired resistance to TRAIL treatment, new recombinant forms of TRAIL and agonistic antibodies are under clinical evaluation for a number of different tumors [26, $57,58]$. To counteract TRAIL-resistance in tumor cells, two strategies have been implemented: combining TRAIL therapy with other anti-tumor therapies [60] or with natural compounds that increase cell susceptibility [61]. For instance, Apigenin, Quercitin and Palmitate have been shown to increase the expression of functional TRAILRs on the surface of tumor cells and to restore TRAILinduced apoptosis $[32,62,63]$. We found in this study that these natural compounds, as well as trabectedin, upregulated TRAIL-Rs on monocytes, and in some cases were able to induce co-localization of TRAIL-Rs into lipid rafts and trigger apoptotic death.

In conclusion, the expression of functional TRAILRs on cells of the mononuclear phagocyte system and their susceptibility to apoptosis indicate that TRAILbased therapies could be an alternative approach to target macrophages in tumors.

\section{MATERIALS AND METHODS}

\section{Drugs and stimuli}

For in vitro experiments Recombinant Super Killer Trail (Human: Enzo Lifesciences; Mouse: Adipogene) was dissolved in PBS-/- $1 \%$ BSA, kept at $-80^{\circ} \mathrm{C}$ and used 300 $\mathrm{ng} / \mathrm{ml}$.

For in vivo experiments Trail Recombinant KillerTRAIL (Alexis) was resuspended in PBS-/- and used $10 \mathrm{mg} / \mathrm{kg}$ i.p every 3 days for 2 weeks.

Glucocorticoids (MP Biomedicals) were used 100uM; hIL-10, hIL-1, hIL-2, hIL-4, hIL-6, hTNF $\alpha$, 
hINF $\gamma$, hTGF $\beta$ (Peprotech) 25 ng/ml; LPS (Alexis) 100 ng/ml; Pam3Cys (Vinci Biochem) $2 \mathrm{ug} / \mathrm{ml}$ according to the manufacture's instructions.

Apigenin, Quercitin (Indena) and trabectedin (Pharmamar) were resuspended in DMSO and used 40uM, 400uM and $10 \mathrm{nM}$ respectively. Palmitate (SIGMA), Indole-3-Carbinole (I3C) resuspended in DMSO and used $800 \mathrm{uM}$ and $100 \mathrm{uM}$ respectively.

\section{In vivo experiment}

The transplantable MNMCA-1 mouse fibrosarcoma were inoculated intramuscularly $\left(5 \times 10^{4}\right.$ cells $)$ in $\mathrm{C} 57 /$ BL/6J mice (Charles River - Calco, Como Italy) and tumor growth was observed over 3 weeks. All mice were used between 6-10 week of age.

Mice, Tumors, and Primary mouse Cells were used in compliance with national (4D.L.N.116, G.U., suppl. 40, 18-2-1992) and international law and policies (EEC Council Directive 86/609, OJ L 358, 1, 12-12-1987; NIH Guide for the Care and Use of Laboratory Animals, US National Research Council, 1996). This investigation was approved by the Animal Care and Use Committee of the Humanitas Clinical and Research Center.

\section{Cell isolation, cell culture and tissue samples}

Human monocytes, neutrophils, and T-lymphocytes from blood of healthy donors were purified through density gradients, as described in Allavena [64], from buffy-coats. Human macrophages were differentiated in vitro from blood monocytes cultured with $25 \mathrm{ng} / \mathrm{ml}$ M-CSF for 5 days and then polarized with LPS (100 ng/ $\mathrm{ml})+\operatorname{IFN}-\gamma(500 \mathrm{U} / \mathrm{ml})$ for M1 macrophages and with IL-4 (20 ng/ml) to obtain M2 ones. Human lymphocytes were antivated in vitro with Ionomycin $(500 \mathrm{ng} / \mathrm{ml})$ and PMA (50 ng/ml).

Mouse blood cells were collected from the eye vein of anesthetized mice and splenocytes from disaggregated spleen and filtered through Falcon strainers. Mouse tumors were cut into small pieces, disaggregated with collagenase $(0.5 \mathrm{mg} / \mathrm{ml})$, and filtered through strainers.

Human tumor tissues and adjacent un-diseased tissues were obtained from patients who underwent surgical treatment in our Institute. Murine normal tissues (spleen, skin, liver, lungs) were obtained from 6 weeks old C57/BL/6J mice from the animal house of our institute. Samples were stained with specific antibodies.

\section{Antibodies}

To study the expression of death receptors in human leucocytes, cells were resuspended in PBS-/- 1X 1\% FBS and stained with anti-human TRAIL-R1, TRAIL-R2 (Enzo Lifesciences), anti-human TRAIL R3 (R\&D Systems) and anti-human Fas (Millipore) used according to the manufacture's instructions. To block their activity were used recombinant human Trail R1/R2 Fc chimera (R\&D Systems), anti-human TRAIL R3 (R\&D Systems) and anti-human Fas (Millipore).

To analyze cell phenotype in mouse blood, spleen and tumor were used PerCp-Rat CD45 (30F11), FITC Hamster CD3 (145-2C11), PE Rat Ly6C and Ly6C (RB6-8C5), FITC Rat Ly6C (AL-21), PE-Cy7 Rat Ly6G (1A8), FITC Rat I-A/I-E (2G9) as well as relative control antibody, streptavidin dye conjugated (APC) (BD Biosciences);Anti-mouse PE CD115 (AFS98), Alexa Fluor 647 CD19 (1D3), PE Rat CD202b/Tie2 (Tec4) (eBioscience); Anti-mouse PE F4/80 (A3-1), FITC Rat CD206 (MR5D3) (AbD Serotec); Biotin-RatCD253(DR5) (N2B2) (Miltenyi Biotec) and finally, Pacific Blue-Rat CD11b (M1/70) (Biolegend). Labeled cells were fixed in PBS-/- $1 \mathrm{X} 1 \%$ formalin. After staining procedures, acquisition was performed by FACS CantoII instrument (BD Biosciences) and analyzed by FACS Diva and FlowJo software version 6.1.1 (BD Biosciences)

To perform immunofluorescence on human tissues were used anti-TRAIL-R1, TRAIL-R2 (Enzo Lifesciences), anti- TRAIL R3 (R\&D Systems), rabbit CD68 (PGM1), rabbit myeloperoxidase, and rabbit CD3 purchased by DAKO; Lipid rafts are detected using Vibrant Lipid Raft Labeling Kits (molecular brobe) used according to the manufacture's instructions.

For mouse tissues were used goat TRAIL R2 (DR5), goat CD31 (R\&D Systems), rat Ly-6G (1A8) (BD Pharmingen) and rat F4/80 (Serotec).

\section{Apoptosis and cell death analysis}

Apoptosis was evaluated through Annexin V/PI staining using the specific detection kit (Immunostep) used according to the manufacture's instructions.

To evaluate caspase 8 activation were used antihuman cleaved-caspase8 (18C8) anti-mouse cleavedcaspase8 Xp Rabbit Mab (D5B2) (Cell signaling) and Fixation/Permeabiliation solution kit (BD Biosciences) according to the manufacture's instructions. Labeled cells were fixed in PBS-/- 1X 1\% formalin.

\section{Statistical analysis}

Statistical analysis was performed using a paired Student's t-test. P-values of less than 0.05 were considered significant

\section{GRANT SUPPORT}

This work was supported by the Italian Association for Cancer Research (AIRC), grant IG to P. Allavena and by the Worldwide Cancer Research grant to P. Allavena. C. Belgiovine was supported by a fellowship from AIRC. 


\section{CONFLICTS OF INTEREST}

The authors declare no competing financial interests.

\section{Authorship contributions}

Contribution: Study supervision, Research design and writing the manuscript: C. Belgiovine and P. Allavena; Performing in vitro experiments and acquistion data: M Liguori, C. Buracchi, S. Pesce; Performing in vivo experiment and acquisition data: $\mathrm{M}$ Liguori, $\mathrm{C}$. Belgiovine, F. Bergomas and M. Sironi.; Perfoming immmunohistochemistry and provided to human undiseased and tumor samples: F. Grizzi and F. Pasqualini; Analysis and interpretation of data (e.g. Statistical analysis, figures) M. Liguori and C. Belgiovine.

\section{REFERENCES}

1. Coussens LM, Zitvogel L, Palucka AK. Neutralizing tumorpromoting chronic inflammation: a magic bullet? Science. 2013; 339:286-291.

2. Hanahan D, Weinberg RA. Hallmarks of cancer: the next generation. Cell. 2011; 144:646-674.

3. Mantovani A, Allavena P, Sica A, Balkwill F. Cancerrelated inflammation. Nature. 2008; 454:436-444.

4. Chittezhath M, Dhillon MK, Lim JY, Laoui D, Shalova IN, Teo YL, Chen J, Kamaraj R, Raman L, Lum J, Thamboo TP, Chiong E, Zolezzi F, Yang H, Van Ginderachter JA, Poidinger $\mathrm{M}$, et al. Molecular profiling reveals a tumorpromoting phenotype of monocytes and macrophages in human cancer progression. Immunity. 2014; 41:815-829.

5. Li H, Yang B, Huang J, Lin Y, Xiang T, Wan J, Chouaib S, Ren G. Cyclooxygenase-2 in tumor-associated macrophages promotes breast cancer cell survival by triggering a positive-feedback loop between macrophages and cancer cells. Oncotarget. 2015; 6:29637-29650. doi: 10.18632/ oncotarget.4936.

6. Lin L, Chen YS, Yao YD, Chen JQ, Chen JN, Huang SY, Zeng YJ, Yao HR, Zeng SH, Fu YS, Song EW. CCL18 from tumor-associated macrophages promotes angiogenesis in breast cancer. Oncotarget. 2015; 6:34758-34773. doi: 10.18632/oncotarget.5325.

7. Mantovani A, Allavena P. The interaction of anticancer therapies with tumor-associated macrophages. J Exp Med. 2015; 212:435-445.

8. Noy R, Pollard JW. Tumor-associated macrophages: from mechanisms to therapy. Immunity. 2014; 41:49-61.

9. Brana I, Calles A, LoRusso PM, Yee LK, Puchalski TA, Seetharam S, Zhong B, de Boer CJ, Tabernero J, Calvo E. Carlumab, an anti-C-C chemokine ligand 2 monoclonal antibody, in combination with four chemotherapy regimens for the treatment of patients with solid tumors: an openlabel, multicenter phase 1b study. Target Oncol. 2015; $10: 111-123$
10. Sandhu SK, Papadopoulos K, Fong PC, Patnaik A, Messiou C, Olmos D, Wang G, Tromp BJ, Puchalski TA, Balkwill F, Berns B, Seetharam S, de Bono JS, Tolcher AW. A firstin-human, first-in-class, phase I study of carlumab (CNTO 888 ), a human monoclonal antibody against CC-chemokine ligand 2 in patients with solid tumors. Cancer Chemother Pharmacol. 2013; 71:1041-1050.

11. DeNardo DG, Brennan DJ, Rexhepaj E, Ruffell B, Shiao SL, Madden SF, Gallagher WM, Wadhwani N, Keil SD, Junaid SA, Rugo HS, Hwang ES, Jirstrom K, West BL, Coussens LM. Leukocyte complexity predicts breast cancer survival and functionally regulates response to chemotherapy. Cancer Discov. 2011; 1:54-67.

12. Pyonteck SM, Akkari L, Schuhmacher AJ, Bowman RL, Sevenich L, Quail DF, Olson OC, Quick ML, Huse JT, Teijeiro V, Setty M, Leslie CS, Oei Y, Pedraza A, Zhang $\mathrm{J}$, Brennan CW, et al. CSF-1R inhibition alters macrophage polarization and blocks glioma progression. Nat Med. 2013; 19:1264-1272.

13. Ries CH, Cannarile MA, Hoves S, Benz J, Wartha K, Runza V, Rey-Giraud F, Pradel LP, Feuerhake F, Klaman I, Jones T, Jucknischke U, Scheiblich S, Kaluza K, Gorr IH, Walz A, et al. Targeting tumor-associated macrophages with anti-CSF-1R antibody reveals a strategy for cancer therapy. Cancer Cell. 2014; 25:846-859.

14. Germano G, Frapolli R, Belgiovine C, Anselmo A, Pesce S, Liguori M, Erba E, Uboldi S, Zucchetti M, Pasqualini F, Nebuloni M, van Rooijen N, Mortarini R, Beltrame L, Marchini S, Fuso Nerini I, et al. Role of macrophage targeting in the antitumor activity of trabectedin. Cancer Cell. 2013; 23:249-262.

15. Vincent M, Sayre NL, Graham MJ, Crooke RM, Shealy DJ, Liscum L. Evaluation of an anti-tumor necrosis factor therapeutic in a mouse model of Niemann-Pick C liver disease. PLoS One. 2010; 5:e12941.

16. Chen $\mathrm{W}, \mathrm{Ma} T$, Shen XN, Xia XF, Xu GD, Bai XL, Liang TB. Macrophage-induced tumor angiogenesis is regulated by the TSC2-mTOR pathway. Cancer Res. 2012; 72:1363-1372.

17. Mercalli A, Calavita I, Dugnani E, Citro A, Cantarelli E, Nano R, Melzi R, Maffi P, Secchi A, Sordi V, Piemonti L. Rapamycin unbalances the polarization of human macrophages to M1. Immunology. 2013; 140:179-190.

18. Mercier I, Camacho J, Titchen K, Gonzales DM, Quann K, Bryant KG, Molchansky A, Milliman JN, WhitakerMenezes D, Sotgia F, Jasmin JF, Schwarting R, Pestell RG, Blagosklonny MV, Lisanti MP. Caveolin-1 and accelerated host aging in the breast tumor microenvironment: chemoprevention with rapamycin, an mTOR inhibitor and anti-aging drug. Am J Pathol. 2012; 181:278-293.

19. Klug F, Prakash H, Huber PE, Seibel T, Bender N, Halama N, Pfirschke C, Voss RH, Timke C, Umansky L, Klapproth K, Schakel K, Garbi N, Jager D, Weitz J, SchmitzWinnenthal $\mathrm{H}$, et al. Low-dose irradiation programs macrophage differentiation to an iNOS(+)/M1 phenotype 
that orchestrates effective $\mathrm{T}$ cell immunotherapy. Cancer Cell. 2013; 24:589-602.

20. Zhao Y, Wang D, Xu T, Liu P, Cao Y, Wang Y, Yang X, $\mathrm{Xu} \mathrm{X}$, Wang $\mathrm{X}$, Niu H. Bladder cancer cells re-educate TAMs through lactate shuttling in the microfluidic cancer microenvironment. Oncotarget. 2015; 6:39196-39210. doi: 10.18632/oncotarget.5538.

21. Almasan A, Ashkenazi A. Apo2L/TRAIL: apoptosis signaling, biology, and potential for cancer therapy. Cytokine Growth Factor Rev. 2003; 14:337-348.

22. Degli-Esposti MA, Smolak PJ, Walczak H, Waugh J, Huang CP, DuBose RF, Goodwin RG, Smith CA. Cloning and characterization of TRAIL-R3, a novel member of the emerging TRAIL receptor family. J Exp Med. 1997; 186:1165-1170.

23. Lee HW, Lee SH, Ryu YW, Kwon MH, Kim YS. Homomeric and heteromeric interactions of the extracellular domains of death receptors and death decoy receptors. Biochemical and biophysical research communications. 2005; 330:1205-1212.

24. Aggarwal BB, Gupta SC, Kim JH. Historical perspectives on tumor necrosis factor and its superfamily: 25 years later, a golden journey. Blood. 2012; 119:651-665.

25. Ashkenazi A. Targeting the extrinsic apoptosis pathway in cancer. Cytokine Growth Factor Rev. 2008; 19:325-331.

26. Ashkenazi A. Targeting the extrinsic apoptotic pathway in cancer: lessons learned and future directions. J Clin Invest. 2015; 125:487-489.

27. Johnstone RW, Frew AJ, Smyth MJ. The TRAIL apoptotic pathway in cancer onset, progression and therapy. Nat Rev Cancer. 2008; 8:782-798.

28. Wiley SR, Schooley K, Smolak PJ, Din WS, Huang CP, Nicholl JK, Sutherland GR, Smith TD, Rauch C, Smith CA, et al. Identification and characterization of a new member of the TNF family that induces apoptosis. Immunity. 1995; 3:673-682.

29. Benedict CA, Ware CF. TRAIL: not just for tumors anymore? J Exp Med. 2012; 209:1903-1906.

30. Daniels RA, Turley H, Kimberley FC, Liu XS, Mongkolsapaya J, Ch'En P, Xu XN, Jin BQ, Pezzella F, Screaton GR. Expression of TRAIL and TRAIL receptors in normal and malignant tissues. Cell research. 2005; 15:430-438.

31. Steinwede K, Henken S, Bohling J, Maus R, Ueberberg B, Brumshagen C, Brincks EL, Griffith TS, Welte T, Maus UA. TNF-related apoptosis-inducing ligand (TRAIL) exerts therapeutic efficacy for the treatment of pneumococcal pneumonia in mice. J Exp Med. 2012; 209:1937-1952.

32. Cazanave SC, Mott JL, Bronk SF, Werneburg NW, Fingas CD, Meng XW, Finnberg N, El-Deiry WS, Kaufmann SH, Gores GJ. Death receptor 5 signaling promotes hepatocyte lipoapoptosis. J Biol Chem. 2011; 286:39336-39348.

33. Prasad S, Kim JH, Gupta SC, Aggarwal BB. Targeting death receptors for TRAIL by agents designed by Mother
Nature. Trends in pharmacological sciences. 2014; 35:520-536.

34. Wu GS, Burns TF, Zhan Y, Alnemri ES, El-Deiry WS. Molecular cloning and functional analysis of the mouse homologue of the KILLER/DR5 tumor necrosis factorrelated apoptosis-inducing ligand (TRAIL) death receptor. Cancer Res. 1999; 59:2770-2775.

35. Biswas SK, Allavena P, Mantovani A. Tumor-associated macrophages: functional diversity, clinical significance, and open questions. Semin Immunopathol. 2013; 35:585-600.

36. Ehrlich S, Infante-Duarte C, Seeger B, Zipp F. Regulation of soluble and surface-bound TRAIL in human T cells, B cells, and monocytes. Cytokine. 2003; 24:244-253.

37. Lamhamedi-Cherradi SE, Zheng SJ, Maguschak KA, Peschon J, Chen YH. Defective thymocyte apoptosis and accelerated autoimmune diseases in TRAIL-/- mice. Nature immunology. 2003; 4:255-260.

38. Song K, Chen Y, Goke R, Wilmen A, Seidel C, Goke A, Hilliard B. Tumor necrosis factor-related apoptosisinducing ligand (TRAIL) is an inhibitor of autoimmune inflammation and cell cycle progression. J Exp Med. 2000; 191:1095-1104.

39. Cretney E, Uldrich AP, Berzins SP, Strasser A, Godfrey DI, Smyth MJ. Normal thymocyte negative selection in TRAILdeficient mice. J Exp Med. 2003; 198:491-496.

40. Sedger LM, Katewa A, Pettersen AK, Osvath SR, Farrell GC, Stewart GJ, Bendall LJ, Alexander SI. Extreme lymphoproliferative disease and fatal autoimmune thrombocytopenia in FasL and TRAIL double-deficient mice. Blood. 2010; 115:3258-3268.

41. Diehl GE, Yue HH, Hsieh K, Kuang AA, Ho M, Morici LA, Lenz LL, Cado D, Riley LW, Winoto A. TRAIL-R as a negative regulator of innate immune cell responses. Immunity. 2004; 21:877-889.

42. Cullen SP, Martin SJ. Fas and TRAIL 'death receptors' as initiators of inflammation: Implications for cancer. Seminars in cell \& developmental biology. 2015; 39:26-34.

43. Bossi F, Bernardi S, Zauli G, Secchiero P, Fabris B. TRAIL modulates the immune system and protects against the development of diabetes. Journal of immunology research. 2015; 2015:680749.

44. Zauli G, Sancilio S, Cataldi A, Sabatini N, Bosco D, Di Pietro R. PI-3K/Akt and NF-kappaB/IkappaBalpha pathways are activated in Jurkat $\mathrm{T}$ cells in response to TRAIL treatment. Journal of cellular physiology. 2005; 202:900-911.

45. Idrissova L, Malhi H, Werneburg NW, LeBrasseur NK, Bronk SF, Fingas C, Tchkonia T, Pirtskhalava T, White TA, Stout MB, Hirsova P, Krishnan A, Liedtke C, Trautwein C, Finnberg N, El-Deiry WS, et al. TRAIL receptor deletion in mice suppresses the inflammation of nutrient excess. Journal of hepatology. 2015; 62:1156-1163.

46. Lunemann JD, Waiczies S, Ehrlich S, Wendling U, Seeger B, Kamradt T, Zipp F. Death ligand TRAIL induces no 
apoptosis but inhibits activation of human (auto)antigenspecific T cells. J Immunol. 2002; 168:4881-4888.

47. Secchiero P, Corallini F, di Iasio MG, Gonelli A, Barbarotto E, Zauli G. TRAIL counteracts the proadhesive activity of inflammatory cytokines in endothelial cells by downmodulating CCL8 and CXCL10 chemokine expression and release. Blood. 2005; 105:3413-3419.

48. Secchiero P, Gonelli A, Mirandola P, Melloni E, Zamai L, Celeghini C, Milani D, Zauli G. Tumor necrosis factorrelated apoptosis-inducing ligand induces monocytic maturation of leukemic and normal myeloid precursors through a caspase-dependent pathway. Blood. 2002; 100:2421-2429.

49. Wynn TA, Chawla A, Pollard JW. Macrophage biology in development, homeostasis and disease. Nature. 2013; 496:445-455.

50. Condamine T, Kumar V, Ramachandran IR, Youn JI, Celis E, Finnberg N, El-Deiry WS, Winograd R, Vonderheide RH, English NR, Knight SC, Yagita H, McCaffrey JC, Antonia S, Hockstein N, Witt R, et al. ER stress regulates myeloid-derived suppressor cell fate through TRAIL-Rmediated apoptosis. J Clin Invest. 2014; 124:2626-2639.

51. Wilson NS, Yang A, Yang B, Couto S, Stern H, Gogineni A, Pitti R, Marsters S, Weimer RM, Singh M, Ashkenazi A. Proapoptotic activation of death receptor 5 on tumor endothelial cells disrupts the vasculature and reduces tumor growth. Cancer Cell. 2012; 22:80-90.

52. Klemm F, Joyce JA. Microenvironmental regulation of therapeutic response in cancer. Trends in cell biology. 2015; 25:198-213.

53. Beatty GL, Chiorean EG, Fishman MP, Saboury B, Teitelbaum UR, Sun W, Huhn RD, Song W, Li D, Sharp LL, Torigian DA, O'Dwyer PJ, Vonderheide RH. CD40 agonists alter tumor stroma and show efficacy against pancreatic carcinoma in mice and humans. Science. 2011; 331:1612-1616.

54. Golden EB, Demaria S, Schiff PB, Chachoua A, Formenti $\mathrm{SC}$. An abscopal response to radiation and ipilimumab in a patient with metastatic non-small cell lung cancer. Cancer Immunol Res. 2013; 1:365-372.

55. Van Overmeire E, Stijlemans B, Heymann F, Keirsse J, Morias Y, Elkrim Y, Brys L, Abels C, Lahmar Q, Ergen C, Vereecke L, Tacke F, De Baetselier P, Van Ginderachter JA, Laoui D. M-CSF and GM-CSF Receptor Signaling
Differentially Regulate Monocyte Maturation and Macrophage Polarization in the Tumor Microenvironment. Cancer Res. 2016; 76:35-42.

56. Qian BZ, Pollard JW. Macrophage diversity enhances tumor progression and metastasis. Cell. 2010; 141:39-51.

57. Fulda S. Targeting apoptosis for anticancer therapy. Seminars in cancer biology. 2015; 31:84-88.

58. Lemke J, von Karstedt S, Zinngrebe J, Walczak H. Getting TRAIL back on track for cancer therapy. Cell death and differentiation. 2014; 21:1350-1364.

59. Secchiero P, Gonelli A, Celeghini C, Mirandola P, Guidotti L, Visani G, Capitani S, Zauli G. Activation of the nitric oxide synthase pathway represents a key component of tumor necrosis factor-related apoptosis-inducing ligandmediated cytotoxicity on hematologic malignancies. Blood. 2001; 98:2220-2228.

60. Amm HM, Oliver PG, Lee CH, Li Y, Buchsbaum DJ. Combined modality therapy with TRAIL or agonistic death receptor antibodies. Cancer biology \& therapy. 2011; 11:431-449.

61. Dai X, Zhang J, Arfuso F, Chinnathambi A, Zayed ME, Alharbi SA, Kumar AP, Ahn KS, Sethi G. Targeting TNF-related apoptosis-inducing ligand (TRAIL) receptor by natural products as a potential therapeutic approach for cancer therapy. Exp Biol Med (Maywood). 2015; 240:760-773.

62. Clancy L, Mruk K, Archer K, Woelfel M, Mongkolsapaya J, Screaton G, Lenardo MJ, Chan FK. Preligand assembly domain-mediated ligand-independent association between TRAIL receptor 4 (TR4) and TR2 regulates TRAILinduced apoptosis. Proc Natl Acad Sci U S A. 2005; 102:18099-18104.

63. Lim SC, Duong HQ, Choi JE, Lee TB, Kang JH, Oh $\mathrm{SH}$, Han SI. Lipid raft-dependent death receptor 5 (DR5) expression and activation are critical for ursodeoxycholic acid-induced apoptosis in gastric cancer cells. Carcinogenesis. 2011; 32:723-731.

64. Allavena P, Signorelli M, Chieppa M, Erba E, Bianchi G, Marchesi F, Olimpio CO, Bonardi C, Garbi A, Lissoni A, de Braud F, Jimeno J, D'Incalci M. Anti-inflammatory properties of the novel antitumor agent yondelis (trabectedin): inhibition of macrophage differentiation and cytokine production. Cancer Res. 2005; 65:2964-2971. 